\title{
O ensino de História e Filosofia da Termodinâmica como meio para o pensamento complexo
}

Louise Trivizol*, Silvia F. de M. Figueirôa**

\section{Resumo}

Esse trabalho apresenta tópicos de natureza das ciências e da história e filosofia da Termodinâmica que consideramos úteis ao ensino, tanto para a educação básica quanto para a formação de professores. Para a apresentação dos tópicos, tomamos como categoria de análise afirmações de Natureza das Ciências ( $\mathrm{NdC}$ ). Nossa concepção de ensino prioriza a transdisciplinaridade e a abordagem de temas afeitos a demandas contemporâneas, como a mudança climática, por exemplo, visando os objetivos expressos pela Alfabetização Científica (AC). O maior desses objetivos sendo a capacitação para tomada de decisões cientificamente informadas para melhor participação cidadã. Justificamos a utilização de temas de NdC pela possibilidade que oferecem de pensar ações pedagógicas alinhadas a concepções contemporâneas em filosofia das ciências, bem como com a historiografia das ciências. A presente pesquisa se insere na necessidade de forçar - procurando romper - pontos frágeis de velhos paradigmas que ainda permeiam e, silenciosamente, conduzem nossa visão de mundo. E que, muitas vezes, negam o benefício de uma atitude crítica e integrativa, informada sobre os meandros e a complexidade da ação humana no mundo, sobretudo a científica. A pesquisa conta com o aporte epistemológico de Ludwik Fleck e busca relações entre a teoria Termodinâmica e o pensamento complexo de Edgar Morin. Tais aproximações podem ser frutíferas aos objetivos da AC, tendo em vista as emergências planetárias que pedem posturas propositivas frente à incerteza do futuro.

Palavras-chave: Ensino de Ciências, Natureza da Ciências, História da Termodinâmica, Incerteza, Complexidade.

Mestranda em Ensino de Ciências e Matemática no Programa Pós-Graduação Multiunidades em Ensino de Ciências e Matemática, Universidade Estadual de Campinas. E-mail: lui.t.assis@gmail.com. ORCID: https:// orcid.org/0000-0001-8727-3412

* Professora Titular da Faculdade de Educação e no Programa Pós-Graduação Multiunidades em Ensino de Ciências e Matemática, Universidade Estadual de Campinas. E-mail: silviamf@unicamp.br. ORCID: https:// orcid.org/0000-0003-0791-2232

10.5335/rbecm.v4i3.12902

http://creativecommons.org/licenses/by-nc-nd/4.0

ISSN: 2595-7376 
O Ensino de Ciências (EC) e áreas afins possuem alguns marcos e condições históricas que engendraram a produção nesse campo e culminaram em questões que nos parecem, atualmente, de grande urgência para a educação científica. A saber, uma revisão nas estratégias de ensino para dar conta das demandas geradas nos campos de História e Filosofia das Ciências (HFC), que há décadas trazem resultados para o Ensino de Ciências. Entendemos que existem conhecimentos a reter da estrutura das ciências que elucidam sua produção, mostrando-se úteis à instrução da população em geral e, sobretudo, aos estudantes e professores de ciências (MATTHEWS, 1995; MOURA, 2014; CLOUGH, 2017; PEDUZZI; RAICIK, 2020; TEIXEIRA et al., 2009; ADURÍZ-BRAVO, 2014). Os professores, em especial, detêm uma posição social cuja capacidade multiplicadora de visões menos estreitas e mais verossímeis das ciências, por nós defendidas, é apreciável. Ao longo dos últimos 40 anos, alguns artigos têm sido, ao mesmo tempo, marcos temporais e "clássicos" na área. Derek Hodson (1985) e Michael Matthews (1995) são exemplos de trabalhos que permitiram algumas generalizações sobre a situação e as possibilidades do ensino científico de forma geral. $O$ diagnóstico da compreensão superficial e estigmatizada das ciências, fortalecida pela imagem popular de que "a Ciência" é um conjunto de conhecimentos descobertos, finalizados e acumulados a partir da aplicação de um método objetivo e neutro, revelou-se sintoma de uma educação científica a demandar reformulações. Os currículos elaborados pela Associação Americana para o Progresso da Ciência (AAAS, em inglês), o Projeto 2061, e o Currículo Nacional Britânico de Ciências deram o tom para uma educação científica que se fortificava ao incorporar as dimensões histórica e filosófica do saber científico, a fim de demonstrar aspectos e fundamentos das ciências que não são captados apenas pelo ensino instrumental dos produtos científicos (MATTHEWS, 1995, p. 67; MOURA, 2014, p. 37). Buscava-se promover uma compreensão científica mais abrangente, ampliando as possibilidades de ensino e aprendizagem, bem como construir um conhecimento sobre as ciências mais verossímil, reconhecendo as dimensões sociais e históricas do saber científico.

Em seu artigo, Hodson (1985) discute vícios na imagem das ciências (empirismo ingênuo, cientista "desinteressado", os mitos de neutralidade científica e unicidade do método, por exemplo) presentes em professores e alunos de ciências, infelizmente ainda persistentes na atualidade (LEDERMAN et al., 2002; EL-HANI, 2006; TEI- 
XEIRA et al., 2009, CLOUGH, 2017). O autor é categórico quanto à necessidade de explicitar a epistemologia que sustenta e coordena as ações e políticas pedagógicas. Sem uma abordagem explícita sobre proposições epistemológicas, isto é, sobre $o$ modo como o conhecimento científico é produzido e o conteúdo histórico das teorias científicas, o que vem a ocupar o papel no imaginário de docentes e estudantes é a referida imagem estática e cumulativa das ciências. Não há produção de saber que não suponha (e produza, também) uma concepção epistemológica (PEDUZZI; RAICIK, 2020, p. 21). Essa é, inclusive, uma das homologias que podemos esboçar entre atividade científica e os atos de ensinar e aprender. Se a atividade científica se refere à construção em "primeira mão" de um conhecimento que se estabilizará pela difusão e uso na comunidade científica, a aprendizagem trata da (re)construção de um conhecimento científico em cada indivíduo, que também se estabiliza ao difundir-se pela vida cultural e social do mesmo. Assim, conhecer um mínimo sobre epistemologia pode auxiliar estudantes na reflexão sobre seu processo de aprendizado, numa atitude metacognitiva, já que epistemologia consiste, de modo geral, em inquirir sobre o "crescimento do conhecimento" via registro/interação do sujeito (JAPIASSÚ; MARCONDES, 2008). Vale frisar que o conhecimento científico e o escolar têm funções e objetivos que diferem em grau e em natureza.

Desde então, a produção acadêmica tem criticado o modelo tradicional de educação científica conteudista e técnica, pautada por uma racionalidade científica instrumentalista que gera visões equivocadas do trabalho científico (PÉREZ et al., 2001; LEDERMAN et al., 2002; PRAIA; GIL-PÉREZ; VILCHES, 2007; CLOUGH, 2017). Tal modelo educacional é popularmente referido como "neopositivista", pois guarda semelhanças com a escola filosófica do Círculo de Viena, do início do século $\mathrm{XX}$, como o culto à ciência como caminho para o progresso da humanidade. No entanto, ainda se mostra necessário interrogar a validade desse paradigma já que ele foi e é, sob muitos aspectos, a concepção educacional mais encontrada em salas de aula (e laboratórios), explícita ou implicitamente. Desde o início do século XX, "a Ciência”, monolito de conhecimento que pairava plácido acima da ignorância humana, percebeu-se em vertigem ao olhar para suas fundações. A crise do pensamento moderno e seus desdobramentos, sabemos, não permitiu que a ênfase numa razão asséptica passasse sem críticas ao longo do último século. A pesquisa em educação científica foi informada e transformada pelas produções que impactaram a História e Filosofia das Ciências (HFC) desde os anos 1960, bem como pelas discussões que 
conformaram o campo dos Estudos Sociais das Ciências (ESC) na década de 1970. As produções dessas áreas, regra geral, denunciaram os critérios científicos de "objetividade", "universalidade" e "observação neutra" como construtos humanos portanto, historicamente determinados e culturalmente situados, sujeitos a vieses particulares. Portanto, há muito dispomos de um forte arsenal de críticas não só à imagem da Ciência (conhecida como visão empírico-indutivista), como também a uma educação científica que pretende refleti-la e ensina tão somente os produtos da ciência como fatos acabados e a-históricos, transmitidos de forma dogmática e acrítica. O reconhecimento da dependência histórica, social e cultural das ciências é um marco na história do pensamento. E enriquece a perspectiva de que não devemos nos furtar em reconhecer a complexidade e conectividade das ciências com as mais variadas manifestações da experiência humana, coletiva e individual.

O panorama acima parece convergir para uma crítica clara. Qual seja: tomar o todo da Ciência por partes dissociadas de conteúdo e um único (suposto) método científico e, por conseguinte, trabalhar apenas com a memorização dos conceitos e o emprego "correto" das técnicas, exclui um universo de saberes sobre os acontecimentos sócio-históricos fundantes e estruturantes do conhecimento. Para uma compreensão mais abrangente de Ciência, deve-se, inevitavelmente, apresentar os produtos atrelados ao seu processo de produção. Posto isso, são variadas as estratégias possíveis para humanizar, contextualizar e complexificar a abordagem da Ciência, ligando-a a outras esferas do saber. Nesse artigo, mobilizaremos algumas das noções reunidas em Alfabetização Científica e Natureza das Ciências para articular pontos que acreditamos frutíferos para o Ensino de Ciências.

\section{História e Filosofia das Ciências (HFC) e Natureza das Ciências ( $\mathrm{NdC}$ ) para a Alfabetização Científica (AC)}

Junto ao debate sobre Ensino de Ciências e à elaboração de currículos condizentes com os desenvolvimentos no campo, é imprescindível discutir os indicadores de aprendizagem, ou seja, de uma alfabetização científica de qualidade. Em ampla revisão bibliográfica, Sasseron e Carvalho (2011) buscam identificar pontos de aproximação e de consenso entre estudiosos da Alfabetização Científica (AC) quanto à definição do termo e às habilidades requeridas por um indivíduo alfabetizado cientificamente. Mantendo em vista as especificidades de cada nível de 
ensino e as diferentes abordagens temáticas e didáticas, a AC prevê que existam conhecimentos gerais ("cultura científica") necessários à vida dos cidadãos, sejam eles futuros cientistas, professores de ciências ou leigos. Evidentemente, a alfabetização, em primeira análise, envolve a capacidade de leitura e compreensão dos conceitos científicos básicos e o uso adequado da linguagem científica, respeitando a estrutura teórica das diferentes ciências. Além disso, as autoras identificam que no cerne da AC objetiva-se a "formação cidadã dos estudantes para o domínio e uso dos conhecimentos científicos e seus desdobramentos nas mais diferentes esferas de sua vida" (SASSERON; CARVALHO, 2011, p. 60). Indicam também que uma AC de qualidade estabelece que é necessário compreender as relações entre Ciência e Sociedade, normas e condutas éticas da comunidade científica, diferenças entre Ciência e Tecnologia e conhecimentos sobre a natureza do fazer científico (SASSERON; CARVALHO, 2011).

Não se trata, porém, de simplesmente adicionar ao conteúdo científico algumas curiosidades e anedotas históricas, justapondo Ciência e História sem uma trama que efetivamente teça a correlação entre as disciplinas - para o caso específico de uma estratégia de ensino via HFC. Tampouco, de detalhar os meandros das interações internas e externas das ciências, sob risco de não se ensinar os conteúdos e pecar pelo excesso, de uma forma ou de outra. O que se sugere é que as estratégias didáticas adotadas pelos professores contextualizem as teorias científicas, tendo como objetivo discutir, de modo mais bem informado, as condições de produção daquele conhecimento, cobrindo um espectro mais amplo de debates sobre as ciências. Para tal, consideramos que há um mínimo necessário, porém não suficiente, de aspectos a serem considerados, além do conteúdo per se. A saber: formas de interação ciência-sociedade, o ethos da comunidade científica e a natureza das ciências e das tecnologias (PÉREZ et al., 2001; LEDERMAN et al., 2002; PRAIA; GIL-PÉREZ; VILCHES, 2007; SASSERON; CARVALHO, 2011). Chamaremos tais características de metacientíficas e, para explicitá-las, nos apoiaremos nos estudos em Natureza das Ciências (NdC). Podemos dizer que essa área nasceu dos esforços em captar o que teria maior valor educacional nas respostas à questão “o que é Ciência?”, a fim de resolver concepções equivocadas sobre ela (PÉREZ et al., 2001; ADURÍZ-BRAVO, 2014; MOURA, 2014; CLOUGH, 2017). Do ponto de vista filosófico, acreditamos que não seria interessante produzir consenso definitivo sobre uma questão aberta como essa. Mas, para fins de educação escolar e formação de professores, é necessário que 
docentes do ensino Básico, principalmente, sejam capazes de oferecer algumas respostas sobre do que se trata, afinal, esse corpo de conhecimento secular (EL-HANI, 2006; TEIXEIRA et al., 2009).

Se já não é suficiente conhecer a ciência a partir apenas de seus produtos, como caracterizar, então, o processo de produção das ciências? Partimos dos pressupostos de que a Ciência é uma atividade coletiva e histórica. Isto é, é produzida por uma comunidade com condutas e normas particulares, sempre em influência mútua com os demais segmentos - político, econômico e cultural. Essas relações, por sua vez, são dinâmicas e cambiantes e, por isso, alteram-se ao longo do tempo, fazendo com que a ciência exiba profunda historicidade. Há muitas aproximações entre o estudo da história e filosofia das ciências e a caracterização de uma possível natureza das ciências. Dado que os estudos historiográficos das ciências somam conhecimentos sobre a atividade científica ao longo dos anos, é possível depreender daí alguns dos fatores internos e externos que influenciam a comunidade na produção dos conhecimentos que vão (ou não) ser incorporados como legitimamente científicos (MOURA, 2014, p. 33). Portanto, é pertinente que existam formas de se sistematizar e comunicar fatores metacientíficos para resolver concepções equivocadas dos educandos sobre as ciências. Há uma extensa literatura disponível sobre o assunto, tanto em artigos publicados no Brasil nas últimas três décadas, tal como reunido em Moura (2014), como também em teses e dissertações. Assim, podemos afirmar que a proximidade entre HFC e o estudo de natureza das ciências, no que tange ao Ensino, é estreita, cooperativa e profícua. A essa interseccionalidade, que discute as particularidades do conhecimento científico e fatores internos e externos responsáveis pela sua produção, convencionou-se chamar de "Natureza das Ciências" e utilizar a sigla NdC ou NOS (inglês). Na definição de William McComas: "Trata-se de um domínio híbrido que mistura aspectos de vários estudos sociais da ciência, que inclui a sociologia, filosofia e história da ciência, que ainda se combinam com pesquisa das ciências cognitivas, como a psicologia” (MCCOMAS, 2008 apud PEDUZZI; RAICIK, 2020, p. 20).

Nas reflexões produzidas em $\mathrm{NdC}$, a vasta maioria dos autores e autoras reconhecem a inexistência de uma natureza das ciências, propositalmente evitando incorrer em equívoco do tipo já mencionado anteriormente, da suposta unicidade do método. Há que se perceber que, submetidas ao escrutínio, as diferentes ciências (físicas, da Terra, biológicas, químicas, sociais etc.) apresentarão peculiaridades 
que as distinguem, e até mesmo dentro de uma mesma ciência, pois áreas de especialização podem adotar estratégias diferentes. Porém, tomando distanciamento e num grau de generalidade do que é interessante ao ensino, alguns teóricos alegam ser possível listar características importantes para conhecimento (LEDERMAN et. al., 2002). Usamos como categorias de análise para essa pesquisa o levantamento realizado por Marrín, Benarroch e Niaz (2013), que investigou trabalhos de cinco grupos de pesquisa em $\mathrm{NdC}$, importantes e largamente referenciados, quanto à convergência de suas afirmações. Os autores avaliam os possíveis consensos entre as afirmações desses grupos e concluem que os aspectos mais consensuais são os relativos "ao cenário onde surgem e são gerenciados os conhecimentos científicos" e à "avaliação do conhecimento científico como produto". Por outro lado, obtêm pouco consenso ou consensos parciais quanto à "fase privada ou de descobrimento", ou seja, os mecanismos de interação da comunidade científica com o mundo físico e entre si, e a "interação entre a fase privada e pública" (ibidem, p. 11). A partir desse levantamento e das categorias por eles sistematizadas, comentaremos alguns aspectos de NdC que apresentam considerável grau de convergência entre os especialistas.

Uma importante constatação da relação ciência-sociedade é que a ciência foi e é produzida por diversas culturas ao redor do mundo ao longo da História. Apesar da aparência europeia veiculada - homens brancos geniais, muitas vezes aristocratas -, os povos árabes, egípcios, hindus, chineses e muitos outros contribuíram na construção do conhecimento que possuímos. Quando nos deparamos com o termo "Ciência" usualmente está omitido o adjetivo "ocidental", de modo que o que tomamos por ciência no geral é, na verdade, um recorte de conhecimentos sistematizados e institucionalizados principalmente no norte global (ROSA, 2006). Também, é contingente à sua construção que esse conhecimento seja assim veiculado, pois faz parte de uma tradição do pensamento ocidental perseguir os ideais de neutralidade, universalidade, generalidade e totalidade, sobretudo após o impacto do Iluminismo na Europa. A produção de conhecimento mescla-se ao local e às pessoas envolvidas na sua produção, tese cada vez mais subentendida nas abordagens contemporâneas da Filosofia, Sociologia e Antropologia das Ciências. Vejam-se, por exemplo, as considerações de Donna Haraway (2009) (produzidas no norte global) sobre a imbricação do sujeito e seu objeto de estudo.

Ainda que caibam a urgência das críticas e a busca por rotas de fuga desse paradigma do pensamento ocidental, ele faz parte da história dos estudos acadê- 
micos em todas as áreas do saber. Tampouco é de nosso interesse desimplicar nosso pensamento, que está fundado no terreno do Ensino de Ciências no Brasil, cujos objetivos curriculares determinam que os conteúdos científicos e metacientíficos são os contidos na ciência ocidental. Para essa pesquisa, tomamos como objeto de estudo a História e Filosofia da Física e a natureza das ciências naturais, pois ela se insere no contexto de aplicação para o Ensino de Física. Portanto, esse é o seu ponto de projeção e, também, de chegada. Alinhamo-nos a Peduzzi e Raicik (2020, p. 22) quando comentam que:

\begin{abstract}
Se por um lado isto [estudo do conjunto de saberes relativos à ciência ocidental] não isenta da crítica o que estudos da literatura, por exemplo, têm designado como colonização do saber (Santos \& Menezes, 2010), a hegemonia da visão eurocêntrica de ciência (e tudo o que ela traz consigo), de outro, mostra a consciência e a prioridade da escolha, sempre necessária e incompleta, na abordagem de temas complexos. De todo modo, conhecer para criticar fortalece a própria crítica.
\end{abstract}

A ciência como possibilidade de conhecimento sobre o mundo é multicultural (MARRÍN et al., 2013). Ao mesmo tempo e exatamente por tal efeito, pode se beneficiar das impressões culturais que incidem sobre ela, pois carrega em si características particulares ao território onde foi concebida. Ademais, ela não só faz parte do repertório cultural e simbólico, como também o produz. Os conhecimentos científicos são, em si, produtos culturais que compõem a tradição de diversas sociedades. Isso nos leva ao próximo ponto: o conhecimento científico não é neutro e, portanto, necessita que os cientistas tomem decisões fundadas em aspectos morais e éticos do uso de novas descobertas científicas e tecnológicas, avaliando possíveis conflitos de interesses. Esse é um tema aberto à discussão mais aprofundada, mas para fins educacionais básicos é suficiente dizer que se busca manter valores éticos e morais acordados pela comunidade científica na resolução de conflitos. A ciência se faz através da interação da comunidade científica com o mundo e entre si, de maneiras diferentes, mas igualmente relevantes e complexas. Assim, faz-se claro também como ideais como "objetividade" podem ser ambíguos quando decisões são tomadas em nível pessoal ou de pequenos grupos. É através da difusão de práticas, condutas e valores epistêmicos (como generalidade, mais simplicidade com maior abrangência) que a comunidade científica se reconhece, se comunica e se multiplica.

Seguindo esse raciocínio, uma característica marcante da metodologia científica é que experimentos devem ser elaborados de modo a serem passíveis de reprodução 
em quaisquer laboratórios adequadamente equipados. Os resultados devem ser comunicáveis e compreensíveis para os especialistas, que podem reavaliá-los, reproduzir o experimento, comunicar seus resultados e assim por diante. Ainda assim, diferentes cientistas realizando o mesmo experimento podem interpretar os dados de forma diferente, a depender da formação prévia de base, preferências pessoais intersubjetivas e pontos de vista distintos. Dentro dos limites da ética científica, isso não constituiria uma atitude de má-fé, porque, na medida em que os cientistas são iniciados na tradição da comunidade científica, eles ganham conhecimento dos valores éticos e epistêmicos compartilhados, i.e., aderem a um "estilo de pensamento", nos termos do epistemólogo polonês Ludwik Fleck (1896 - 1961) (DELIZOICOV, 2002; CONDÉ, 2018). Ainda assim, dentro dos coletivos científicos existem diferentes estilos de pensamento e sempre haverá uma parcela de idiossincrasias envolvidas com a atividade científica que são importantes ao conflito de teorias, para uma dialética e constante renovação do conhecimento. O físico Ludwig Boltzmann (1844 - 1906), por exemplo, durante toda sua vida acadêmica, defendeu a tese do pluralismo teórico. Um posicionamento a favor de uma pluralidade epistêmica, que daria os recursos necessários ao desenvolvimento ("progresso") das ciências em direção a melhores representações e modelos do mundo físico, melhorando nossa compreensão sobre a Natureza (VIDEIRA, 2006). O pluralismo teórico, então, só seria possível a partir da aceitação de diferenças de interpretação e proposição de teorias dentro da comunidade científica, não recaindo em dogmatismos e na razão asséptica anteriormente mencionada que tenciona eliminar divergências.

Ainda, é importante reforçar que nem os experimentos conseguem ser elaborados sem nenhuma prévia teórica (hipóteses, por exemplo), nem os dados empíricos são interpretados sem o aporte das teorias científicas e de uma epistemologia (declarada ou não). Há longas discussões de diversos filósofos das ciências e mesmo de cientistas sobre a inseparabilidade teoria-observação, que consta na História das Ciências como advento fundador da ciência moderna no século XVII, com a "Revolução Científica". A sintese entre teoria e prática, pode-se dizer, foi iniciada pelo método implementado por Galileu e magistralmente realizada por Isaac Newton, resultando na unificação dos movimentos da Terra e dos céus (PRIGOGINE; STENGERS, 1984; ROSA, 2006). O ser humano começa a inquirir a Natureza, fazer-lhe perguntas e realizar medidas. A Natureza, por sua vez, haverá sempre de responder às perguntas na mesma linguagem em que elas foram formuladas - por isso a importância da epistemologia. 
Essa discussão acerca do nosso diálogo com a Natureza, da relação teoria-observação, de qual dinâmica existe entre esses dois pilares da interação humana com o mundo físico pode ser encaixado na categoria de Marrín et al. (2017) como "a fase privada ou de descobrimento", que, como vimos, oferece pouco consenso entre os especialistas de NdC. No campo de produção da História e Filosofia das Ciências e dos Estudos Sociais das Ciências, há ainda menos consenso. Há grande variedade de interpretações, complementares, contingentes, divergentes e um mosaico de teorias do conhecimento com diferentes recortes e ferramentas de análise. Portanto, para uma questão como essa, valemo-nos do princípio do pluralismo teórico de Boltzmann.

Em suma, frisamos que as afirmações sobre natureza das ciências, mais ou menos consensuadas, devem nortear os processos pedagógicos para alfabetização científica. Em sala de aula, podem ser abordadas como temas e questões geradoras de debates, de modo que possibilitem diagnosticar as visões "distorcidas" dos alunos, ao mesmo tempo em que se discutem possíveis ambiguidades na interpretação dos temas e questões (MARTINS, 2015). Assim, há incentivo a uma aprendizagem dedicada à construção de atitudes investigativas e crítico-reflexivas, que trabalhe a metacognição dos estudantes. Com efeito, Peduzzi e Raicik (2020, p. 21) alertam que "princípios descontextualizados e declarativos, de enunciados sucintos e passíveis de ambiguidade, presentes em listas que reúnem aspectos teoricamente consensuais sobre a natureza da ciência, com frequência são distorcidos e mal compreendidos”. Portanto, o ensino de natureza das ciências deve ser declaradamente antidogmático e dialógico, sob pena de incorrer em simplificações e visões igualmente distorcidas das ciências como um empreendimento duvidoso, sem escrúpulos e sem valor de verdade, como alegam as quimeras do movimento negacionista deste século.

Ainda, sobre a circulação dos saberes científicos entre diferentes coletivos da comunidade científica (fase privada) e desta com o setor público, Höttecke e Allchin (2020) oferecem material bastante recente sobre como o conhecimento científico é "consumido" pelos "cidadãos-consumidores" - isto é, a partir da mediação da mídia tradicional (televisão, jornais e revistas eletrônicas ou não) e das instituições científicas de fomento e/ou divulgação - os "gatekeepers", guardiões (do conhecimento), em tradução livre. Também incluem os novíssimos desafios e deslocamentos provocados pela introdução da internet e as redes sociais como entidades personalizadas, autorreguladas e reguladoras da difusão de conhecimento. Por isso, eles avançam e advogam por uma NOSIS (Natureza das Ciências na Sociedade, em inglês), que 
deve integrar os currículos de ciências e representar objetivos da alfabetização científica, provendo capacidade de acesso e análises de qualidade das informações científicas, auxiliando os cidadãos para a tomada de decisões cientificamente informadas. Assim, cidadãos e cidadãs poderiam empoderar-se e "participar no discurso público e tomada de decisões ativas quando a ciência e políticas públicas se atravessam" (ibidem, tradução nossa, p. 643). Partilhamos dessa perspectiva: um dos principais objetivos da educação científica é conferir maior autonomia aos cidadãos para identificarem as fontes adequadas e filtrarem as informações no processo de tomada de decisões. Seja de interesses particulares (sobre a própria saúde, por exemplo), sociais ou ambientais, deve-se compreender que as ciências oferecem bases seguras, pois são fundamentadas em valores compartilhados e cujo mecanismo de dependência epistêmica cria uma rede de autorregulação e garantia de qualidade (HÖTTECKE; ALLCHIN, 2020).

Finalizamos essa seção recuperando as premissas de uma Alfabetização Científica de qualidade: objetivar, especialmente, uma formação para o desenvolvimento pessoal, promovendo inserção na cultura científica através de um conjunto mínimo de compreensão dos produtos e dos processos. Parece haver um consenso, na bibliografia aqui citada, ao redor da tomada de decisões como ponto de chegada da alfabetização científica. Por isso, em linhas gerais, a AC deve assegurar o direito de todas as pessoas de conhecer e compreender, de letrar-se no conjunto de saberes tecno-científicos construídos histórica e coletivamente a partir de contribuições de todo o mundo, que se cruzam na produção de um conhecimento que se pretende universalmente comunicável. Na seção a seguir, apresentaremos alguns aspectos da Termodinâmica, a fim de exemplificar a visão de natureza das ciências expressa nesse artigo e seu potencial educacional. Intentamos também, ao trazer parte do conteúdo da teoria em clara articulação com uma epistemologia, iniciar o traçado de algumas rotas rumo a um pensamento que contemple o paradigma da complexidade.

\section{Incerteza como paradigma: a Termodinâmica na virada do século $X X$}

Na História da Física, as décadas iniciais do século XX destacam-se como a época da crise do pensamento científico, seguida de profundas reformulações e de uma revolução conceitual. O Círculo de Viena, já mencionado, foi um movimento que 
teve um papel fundamental na dinâmica dos que tentavam apresentar soluções aos novos problemas que emergiam nas ciências. Problemas que envolviam perguntas sobre quais seriam os objetos de estudo "legítimos" das ciências e a forma "correta" de abordá-los. O chamado positivismo lógico assume a primazia da observação: os dados empíricos deveriam ser formulados em linguagem objetiva e direta - ou seja, a lógica, cujas sentenças se valeriam da precisão matemática para atestar ou refutar as observações. Para tal, era necessário evitar os objetos metafísicos do pensamento, entidades não-observáveis, para garantir a verificabilidade das teorias. À época, havia uma querela entre físicos e filósofos (VIDEIRA, 2006), cujo detalhamento não cabe aqui. Por fim, o Círculo de Viena não emplacou seu estilo de pensamento, que se mostrou incompatível e, de certa forma, insuficiente na abordagem das questões nascentes da virada do século XX. Como exemplo, podemos evocar as famosas duas nuvens às quais se referiu William Thomsom (1824 - 1907) que obscureciam a luz das teorias científicas desenvolvidas ao longo do século XIX, a saber; 1) a teoria ondulatória da luz, sugerindo a existência indetectável do éter e 2) a teoria da equipartição de energia de Maxwell-Boltzmann, uma teoria atomista (SCHULZ, 2007). Essas duas grandes nuvens só foram satisfatoriamente dirimidas pelas teorias Relativística e Quântica, respectivamente, que, sabemos, forçaram rupturas com o paradigma vigente.

Compreendemos, portanto, que ambas as teorias - Mecânica Quântica e Mecânica Relativística - ocupam os cânones no estilo de pensamento contemporâneo das ciências físicas, evidenciando a superação dos limites do paradigma newtoniano, tanto para as entidades microscópicas quanto para distâncias e massas astronômicas. Antes de prosseguir, cabe expor rapidamente algumas qualidades do paradigma newtoniano importantes para compreender a oposição em que se colocam as teorias científicas do século XIX e XX, orientadas pelo aparecimento da incerteza no mundo físico. Simplificadamente, o paradigma newtoniano é o conjunto de práticas, estratégias e visões de mundo ancoradas na mecânica clássica, cuja abordagem dos problemas compreende os fenômenos a partir da ação à distância de forças sobre corpos maciços que, por sua vez, descrevem trajetórias em um plano cartesiano (PRIGOGINE; STENGERS, 1984; PRIGOGINE; FERREIRA, 1996). Nessa abordagem, conhecendo-se precisamente as condições iniciais seria possível determinar a trajetória futura de qualquer corpo material, num sistema de referência onde o tempo é absoluto e reversível. Por isso, também, costuma-se chamar 
o paradigma newtoniano de determinista. A visão determinista sobre o mundo usa comumente analogias como mundo-máquina, o relógio e a Natureza como um $a u$ tômato (PRIGOGINE; STENGERS, 1984). A previsibilidade aparece no paradigma newtoniano como característica muito marcante. Assim, é compreensível porque a Física Quântica, ao inserir o conceito de incerteza como elemento indelével da observação (vide o Princípio de Incerteza de Heisenberg), e a Física Relativística, ao questionar o estatuto absoluto do tempo, tecendo o espaço-tempo não-euclidiano e relativo ao observador, desferem golpes fatais à Física Newtoniana.

Nossa pesquisa, porém, volta a atenção a outro campo da Física, um pouco anterior e com uma história também muito rica: a Termodinâmica Clássica. Ainda que profundamente inspirada pelo paradigma mecanicista, a Termodinâmica cuja gênese encontra-se nas realizações tecnológicas da Revolução Industrial no século XVIII - desenvolveu-se de tal forma que criou condições favoráveis para o rompimento com a tradição da Física Newtoniana. Veem-se emergir na Termodinâmica conceitos inéditos e impensáveis pelo paradigma mecanicista determinista, como entropia e irreversibilidade. Devido a sua abordagem fenomenológica, i.e., de observação e descrição dos fenômenos sem necessariamente explicar sua natureza, a Termodinâmica Clássica passou incólume pelas revoluções científicas que mudaram profundamente as concepções da natureza da matéria. Albert Einstein (1879 - 1955) chegou a declarar: "It is the only physical theory of universal content concerning which I am convinced that, within the framework of applicability of its basic concepts, it will never be overthrown ${ }^{1}$ ". (EINSTEIN, 1949 apud KLEIN, 1967)

Ilya Prigogine, nascido russo em 1917 e naturalizado belga, foi um cientista e difusor de uma filosofia da ciência a partir da Termodinâmica que lhe rendeu a alcunha de "poeta da Termodinâmica”. Ganhou o Prêmio Nobel de Química de 1977 por suas contribuições para a termodinâmica do não-equilíbrio, particularmente a teoria de estruturas dissipativas. Prigogine argumenta, em um capítulo do seu livro “O fim das certezas” (1996), como a Mecânica Quântica, apesar de sua imagem popular disruptiva, mantém alguns dos fundamentos do paradigma newtoniano. É de conhecimento de qualquer estudante de física de nível superior que, após a observação de um sistema quântico (até então, em estado indeterminado de superposição), é possível escrever uma equação determinística de sua evolução temporal. Não obstante, o tempo na teoria quântica, assim como na mecânica clássica, também ocupa meramente a posição de parâmetro, uma abstração matemática. A 
Termodinâmica é fundamentalmente orientada pelos conceitos de incerteza, por vezes, da imprevisibilidade e do tempo que nos atravessa, irreversivelmente, como uma "flecha do tempo", termo cunhado pelo físico Arthur Eddington (1882 - 1944) (PRIGOGINE; STENGERS, 1984; PRIGOGINE; FERREIRA, 1996). Tais expressões do mundo físico jamais haviam sido captadas em nenhuma outra teoria científica até então. E, ainda assim, a Termodinâmica não goza, como área da Física, da mesma popularidade das teorias quântica e relativística, ainda que nos ofereça debates frutíferos e desconcertantes sobre a natureza da matéria e os fenômenos do mundo físico.

Muito se argumenta sobre a importância de trazer temas de Física Moderna às escolas, como forma de atualizar os currículos da educação científica e tratar dos temas contemporâneos imbricados em nossa experiência cotidiana (MOREIRA, 2000). Sabemos, porém, que ainda há entraves na implantação de novidades nos currículos, em que a inserção ou retirada de temas é, no mínimo, burocrática, pois necessita de reelaboração por uma cadeia de instituições envolvidas com a Escola, e, no limite, política, já que envolve disputas de poder entre campos disciplinares. Não queremos diminuir a necessidade de renovação dos currículos, pelo contrário, buscamos rotas alternativas para facilitar o acesso a temas que possam suscitar debates sobre as conquistas mais recentes da Física, bem como sobre a natureza das ciências. Por isso, sugerimos a Termodinâmica, um campo da físico-química que já integra os currículos escolares brasileiros e que tem capacidade de construir relações inter- e transdisciplinares por seu caráter de fronteira e seu rico contexto histórico-social de formação.

No século XVIII, ao longo da Revolução Industrial, as tecnologias de geração de energia tiveram um crescimento e profusão acelerados, em função da demanda mercantil dos países europeus. Um exemplo muito conhecido são as máquinas a vapor que geraram trabalho mecânico para colocar locomotivas e outros eixos rotativos em movimento. Não obstante, esse aperfeiçoamento para realizar movimento giratório foi numa etapa posterior a sua concepção, pois a máquina era inicialmente voltada à função de bombear água para fora das jazidas de carvão mineral que, dada a exploração predatória das fontes vegetais e minerais de energia, criou a necessidade de buscar combustíveis em cavas cada vez mais profundas, que acabavam inundadas pelo lençol freático (PÁDUA et al., 2008). É sabido e largamente referido na história da Termodinâmica que a tecnologia das máquinas térmicas foi desenvolvida antes 
mesmo de uma teoria das mesmas, isto é, da matematização, fundamentação teórica e elaboração das leis acerca dos processos físicos envolvidos na transformação de calor em trabalho mecânico (PÁDUA et al., 2008). Esse fato histórico é de grande valia para exemplificar como as ciências também se desenvolvem na direção oposta da que se pensa usualmente, qual seja, partindo da "descoberta" de um fato científico, seguida da ampliação e refinamento da teoria e, posteriormente, aplicação direta na construção de objetos tecnológicos. As máquinas térmicas eram aparatos tecnológicos relativamente comuns que permitiram a expansão da Revolução Industrial. No entanto, o interesse pelo seu funcionamento permaneceu por muito tempo restrito aos seus aspectos técnicos, estudado por engenheiros para fins de aperfeiçoamento das máquinas e melhor desempenho.

Como dito anteriormente, buscamos uma educação científica que possa abordar os problemas contemporâneos em sua interdependência com outras esferas do saber, que na escola estão disciplinarizadas como filosofia, sociologia, geografia, química, biologia, história etc. Os objetivos do ensino de ciências devem contemplar que os estudantes disponham de (um mínimo de) conhecimento científico para participar dos debates públicos, da construção da sua própria história e a de sua comunidade. Conforme Höttecke e Allchin (2020), o caso da mudança climática e sua relação com a extração de combustíveis fósseis é um debate que mobiliza um conjunto bem amplo de atores sociais e políticos, cuja relevância é de interesse global e tem força para determinar o futuro de países e da Terra como um todo. Sugerimos que um dos conhecimentos científicos básicos que poderiam auxiliar na compreensão geral e, esperamos, gerar mais engajamento nesse debate, são conceitos e relações básicas da Termodinâmica: as transformações de calor em trabalho e a produção de entropia. Numa situação de ensino, portanto, teríamos espaço não só para discutir a emergência climática, como poderíamos tecer, junto a esse problema, o conteúdo científico da segunda lei da termodinâmica.

O desenvolvimento da teoria Termodinâmica, que crescia em atenção ao longo do século XIX com trabalhos de grande impacto como os de Sadi Carnot (1796 1832), sobre a potência motriz do fogo, e James Joule (1818 - 1889), com a equivalência entre trabalho e calor, por exemplo, estabeleceu novos fundamentos para o pensamento sobre a natureza e demonstrou a impossibilidade de certos processos, colocando limites e novas fronteiras para o conhecimento científico - como foi o caso das máquinas de moto-perpétuo. Poderíamos citar muitos estudiosos que contribuí- 
ram fortemente para construção das bases para a Termodinâmica Clássica. Por ser uma "teoria de princípios", como diria Einstein (KLEIN, 1967), suas leis podem ser elaboradas em variadas sentenças que identifiquem e descrevam o mesmo fenômeno observável. De acordo com Pádua (et. al., 2008), dentre os cientistas que foram decisivos na formulação da primeira lei da termodinâmica (conservação de energia), Rudolf Clausius (1822 - 1888) deu contribuição muito significativa. Em especial, porque rompeu com a teoria do calórico ${ }^{2}$, teoria que ao longo dos séculos XVIII e XIX contava com vários adeptos tentando estabelecê-la na comunidade científica, mas que não respondia a questões que a proposição de Clausius pôde resolver melhor. Segundo Pádua (et. al., 2008, p. 77):

Clausius apresentou argumentos rejeitando a teoria do calórico em favor de um princípio que estabelecia a equivalência entre o trabalho e o calor. [...] A recusa foi baseada naquilo que se tornou a primeira lei da Termodinâmica: toda vez que trabalho é produzido por meio de calor, é consumida uma quantidade de calor equivalente à quantidade de trabalho produzida. Uma premissa que Clausius acreditava ter sido firmemente estabelecida por meio dos experimentos de Joule.

Katya Aurani (2018) apresenta um detalhamento do conceito inicial de entropia elaborado por Clausius. Clausius sabia, conforme Carnot, que "a produção de calor sozinha não é suficiente para dar origem à potência motriz do fogo; é necessário que haja o frio; sem isso o calor seria inútil" (CARNOT, 1824 apud AURANI, 2018). Por conta disso, Clausius chega à conclusão de que a única direção espontânea para a passagem do calor é de uma fonte quente para a fria, o que indica uma gênese das noções de irreversibilidade e direção preferencial dos processos espontâneos, formas alternativas de compreensão da segunda lei (AURANI, 2018). Então, explorando algebricamente a expressão do princípio de equivalência das transformações, Clausius concluiu que nos processos reversíveis as transformações compensam umas às outras (soma algébrica igual à zero), enquanto que em processos irreversíveis deveria haver uma soma positiva, "pois as transformações negativas não poderiam ocorrer sem compensação" (ibidem, grifo nosso, p. 158). Em seguida, explorando a conservação de energia para processos não-cíclicos, Clausius julgou necessário inserir o conceito de desagregação, relativo ao "arranjo dos constituintes das substâncias, e que cresce por efeito do calor, à medida que aumenta a dispersão no corpo" (ibidem, p. 159).

Com isso, gostaríamos de evidenciar que as noções de equivalência, compensação e desagregação são basilares na concepção da entropia e, no entanto, ainda 
que permaneçam coerentes com a concepção moderna da termodinâmica, parecem ter sido totalmente abandonadas e ignoradas pelos manuais e, consequentemente, por professores e professoras. Por isso, insistimos na validade da ideia de que os processos de transformação energética não ocorrem sem uma compensação, qual seja, a passagem de calor para uma fonte fria e o aumento da entropia nos sistemas fechados (que, nos termos de Clausius, significa a desagregação, dispersão da energia aproveitável). Diante de temas pungentes como a mudança climática, largamente reconhecida pela comunidade acadêmica desde 1990 e que figura no último Painel Intergovernamental sobre Mudanças Climáticas (IPCC, em inglês) como consequência de ações antrópicas da queima de combustíveis fósseis desde a Revolução Industrial (IPCC, 2021), não podemos jamais imaginar que estamos em posição confortável para continuar retirando recursos da Natureza da mesma forma. Não estamos assistindo passiva e externamente aos fenômenos naturais se desenrolarem como em uma peça sobre um palco. A disjunção cartesiana entre o homem e a natureza, que informou o paradigma newtoniano, não existe. Ao contrário, estamos interligados e somos a manifestação da própria natureza se produzindo, energia e matéria se transformando e se dissipando. De modo geral, acreditamos que a compreensão desses princípios científicos básicos pode ser caminho para imaginarmos soluções mais criativas e integrativas para a questão energética, reconhecendo a impossibilidade de extrair energia do sistema Terra sem que haja uma via de compensação com a qual, cedo ou tarde, teremos que lidar.

Portanto, a entropia é o conceito representante da segunda lei da termodinâmica e é, por isso, o que faz a distinção entre os processos reversíveis (variação de entropia igual a zero) e os irreversíveis (variação de entropia diferente de zero). Parece-nos importante dizer também que, apesar de muitos associarem a entropia com a medida de "desordem" do sistema, essa é uma simplificação grosseira da potência criadora da entropia. Em um movimento dialético e recursivo fascinante, entropia e vida misturam-se: a entropia é responsável pelas flutuações estatísticas que originam estruturas complexas, altamente organizadas, das quais podem emergir funções biológicas e a vida. A vida, por sua vez, é um dos fenômenos naturais que tem capacidade de reduzir a entropia dos sistemas abertos. Mas esse é um assunto longo, a merecer dedicação especial. Para os fins deste trabalho, trazemos a citação a Murray Gell-Mann, feita por Prigogine, sobre a relação entre entropia e informação (ou a falta dela) para indicar que não se trata tão somente de desordem e dissipação: 
A entropia e a informação estão estreitamente ligadas. Na realidade, a entropia pode ser considerada uma medida da ignorância. Quando sabemos apenas que um sistema está num dado macroestado, a entropia do macroestado mede o grau de ignorância acerca do microestado do sistema, contando o número de bits de informação adicional que seria necessário para especificá-lo, sendo todos os microestados [por exemplo, as diferentes configurações possíveis das partículas de um gás a determinada pressão p] no macroestado [i.e., a pressão p] considerados igualmente prováveis (GELL-MANN, 1994 apud PRIGOGINE; FERREIRA, 1996)

Intentamos evidenciar que a natureza é essencialmente probabilística, como nos avisa também a Mecânica Quântica. Incerta, não porque nos faltem parâmetros adequados para descrevê-la, mas porque a natureza é um mar de possibilidades flutuantes que transbordam dos estreitos canais das trajetórias determinísticas. A entropia é uma propriedade emergente de sistemas de muitos corpos cuja interação persistente cria correlações que não conseguem ser descritas pela mecânica newtoniana (ibidem). O paradigma da incerteza e tudo que ele supõe - a irreversibilidade do tempo, a dissipação de energia, a luta constante entre a ordem e o caos - nasceu, de fato, com a Termodinâmica. Há muito mais indeterminação na própria ontologia da matéria do que a certeza e previsibilidade que supunham a mecânica clássica.

Por fim, citamos Pádua et al. (2008) sobre a segunda lei da termodinâmica: "De forma absolutamente sintética, podemos dizer que a segunda lei traz em si um Princípio de Evolução, que de certa forma traduz o caráter irreversivel dos processos naturais. Estes fenômenos 'seguem'o sentido da 'flecha do tempo' como dizia Arthur Eddinton" (ibidem, p. 82). Retomando a ideia evolucionária para os sistemas termodinâmicos e demais sistemas de corpos interagentes, Ludwik Fleck, pesquisador de ciências médicas e filósofo da ciência polonês, compreende o desenvolvimento e evolução das ciências em analogia ao conceito biológico de evolução, devido à sua proximidade com as ciências da vida (DELIZOICOV, 2002; CONDÉ, 2018). Assim, a termodinâmica torna-se também uma teoria relevante e candidata a objeto epistemológico para a construção de uma teoria do conhecimento, pois segundo a epistemologia de Fleck, "Os fatos científicos são condicionados e explicados sócio-historicamente. Interdependentes, formam um continuum em que as experiências do presente estão ligadas às do passado e estas se ligarão às do futuro" (DELIZOICOV et al., 2002, p. 57). Em decorrência, reafirmamos que a ciência é contingente. Como poderia, então, a história das ciências ser diferente? A ciência conta a sua própria história. E o tempo não é, de forma nenhuma, uma invenção, uma abstração matemática, 
uma ilusão. Se somos algo, o somos por causa do tempo, pois é exatamente o que permite a ordenação (e o decaimento) do mundo ao nosso redor. É o que permite o vir a ser do novo e a existência do velho. Como diria o filósofo Henri Bergson (1859 -1941), grande inspiração para as elaborações tanto científicas quanto filosóficas de Prigogine: "o tempo é o que impede que tudo seja dado de uma só vez" (BERGSON, 1920 apud PRIGOGINE; FERREIRA, 1996, p. 21). A incerteza e indeterminação são o que nos dão algum sentido de liberdade para construir nosso próprio caminho, pois tudo permanece possível até que seja real.

Para encaminhar outras possibilidades desse diálogo, indicamos que produções em Termodinâmica e áreas afins, a partir dos anos 1950, contribuem imensamente para melhor entendimento do paradigma da incerteza, ou o paradigma complexo, como também é chamado. Citamos: sistemas complexos, transições de fase, sistemas abertos longe do equilíbrio, estruturas dissipativas, fractais, auto-organização etc. (PRIGOGINE; FERREIRA, 1996). Apesar de estar além do conteúdo escolar, a leitura de trabalhos como o de Ilya Prigogine, e suas colaborações com Isabelle Stengers, pode ser de grande aprendizado para professores em formação. A colaboração prolífica, didática e profundamente transdisciplinar entre Prigogine e Stengers - autora relevante no debate contemporâneo - oferecem reflexões ricas não só no campo especializado da físico-química, como também da história e filosofia das ciências, das interfaces da ciência com a sociedade e as perspectivas de futuro do desenvolvimento técnico e científico e seus efeitos no destino planetário.

\section{O pensamento complexo e seus operadores}

Durante a escrita desse artigo, Edgar Morin completou 100 anos de vida. Esse pensador que há um século experiencia e participa ativamente no fluxo de acontecimentos do mundo é um dos primeiros nomes que surgem em buscas sobre o paradigma da complexidade. Apesar de não reivindicar a sua invenção - que, em verdade, aparece em 1934 com o filósofo da ciência Gaston Bachelard na obra "O novo espírito científico" -, é considerado o "grande artesão" da complexidade (ALMEIDA et al., 1997). Dentre seus mais de 70 livros, destacam-se os seis volumes da obra "O método", em que expõe suas ideias em atravessamento com as mais diversas áreas do conhecimento: educação, filosofia, sociologia, psicologia e áreas afins, as quais constituem uma matriz transdisciplinar que caracteriza seu pensamento. $\mathrm{O}$ nome 
da obra não foi escolhido levianamente, Morin é consciente das controvérsias ao redor da busca de um método receituário para alcançar respostas definitivas. Ao invés disso, faz a distinção entre método e metodologia:

Freqüentemente, esse termo [método] é confundido com metodologia, o que enrijece seu caráter programador; método aqui é entendido como uma disciplina do pensamento, algo que deve ajudar qualquer um a elaborar sua estratégia cognitiva, situando e contextualizando suas informações, conhecimentos e decisões, tornando-o apto para enfrentar o desafio onipresente da complexidade (MORIN, 2003, p. 12).

Edgar Morin mantém a precisão quando evoca a ubiquidade da complexidade. Chama atenção para que a palavra "complexo" não seja utilizada como um termo "tapa buracos", para não encerrar sob essa alcunha uma miríade crescente de problemas. Ao reconhecer a natureza complexa dos problemas do século - as "emergências planetárias” (Bybee apud PRAIA, GIL-PÉREZ; VILCHES, 2007, p. 145) -, devemos enfrentar o debate, adentrar a complexidade e buscar compreender seus mecanismos (ALMEIDA, 1997; MORIN, 2000; 2003). Afinal, o mundo (físico e não-físico) desenrola-se de forma irreversível e quase sempre incerta. Isso, no entanto, não deve gerar pânico ou medo, a ponto de ser imobilizante ou fazer desviar o olhar. Deve sim, ser premissa para "ficar com o problema", como nos indica Haraway no título do seu livro publicado em 2016, "Staying with the trouble”. Para tal, é preciso ferramentas, operadores cognitivos, que permitam entrar na densa atmosfera dos fenômenos complexos. Em livros mais recentes, Morin condensou suas ideias em temas que considera mais urgentes: "Educar na Era Planetária" (2003) e "Sete Saberes Necessários para a Educação do Futuro" (2000). Neles, reapresenta e reelabora seu método como estratégia de ação aberta, capaz de responder às intempéries de navegar em um mar de incertezas, cercado por um arquipélago de certezas, analogia a que recorre com frequência para comunicar sua filosofia.

Passamos à apresentação de alguns dos operadores morinianos que, não surpreendentemente, auxiliam a compreensão da sua própria filosofia, já concebidos em um movimento circular e dinâmico de observar e descrever a si mesmo:

O primeiro deles é a noção de sistema. Um sistema é o conjunto de partes diferentes, unidas e organizadas. Assim, por exemplo, a sociologia define a sociedade como um sistema [...] não podemos conhecer a sociedade a partir de indivíduos e grupos tomados isoladamente. É preciso juntar as partes ao todo, e o todo às partes (ALMEIDA et al., 1997, p. 17). 
A noção de sistema não é cara somente a Morin, mas também às ciências no geral e, em particular, às ciências físicas. Apesar da citação colocá-la como um operador, pode-se referir à noção de sistema como algo similar a uma "lei zero" para compreender os demais operadores. Fica clara aqui a relevância que o ensino de ciências naturais (através da Termodinâmica, por exemplo) adquire para o aprendizado de conceitos centrais e amplamente compartilhados por diversas áreas do saber. Temos também o princípio da circularidade ou recursividade, que supõe uma dinâmica de causa-efeito retroativa, "onde o próprio efeito volta à causa" (ibidem, p. 18) e que se retroalimenta, num tipo de autopoiesis, i.e., a realização de si mesmo. Desse modo, as invenções são, ao mesmo tempo, inventoras de si mesmas e de outras invenções, que mantêm o princípio de recursividade girando. Essa é uma das dimensões do que conferimos às ciências como o caráter contingente do pensamento científico: as invenções estão inscritas nas circunstâncias do momento de sua produção, sendo determinadas por elas, mas também permanecendo imprevisíveis até que tenham sido, de fato, concretizadas. Esse princípio oferece-nos a possibilidade de pensar uma causalidade que se contrapõe à causalidade linear, característica do paradigma newtoniano.

O operador hologramático usa o objeto holograma: uma imagem tridimensional na qual um ponto contém informação referente à totalidade da imagem. Morin exemplifica muito bem esse operador recorrendo à função das células nos organismos vivos. Em uma célula, que se pode chamar de unidade constituinte de seres vivos, encontramos material genético que carrega informação sobre a totalidade daquele ser. Ao menos, informação suficiente para garantir a reprodução de si mesmo (autoprodução). O operador hologramático "diferencia-se da visão holística, uma vez que, para Morin, o todo é, por vezes, maior ou menos do que a soma das partes" (ALMEIDA et al., 1997, p. 33). Estendendo esse operador ao nível social, Morin argumenta que cada indivíduo (uma parte da sociedade) também carrega em si um pouco do "todo" ao ser portador de cultura - "as proibições, as normas, a linguagem e, finalmente, a presença da sociedade em nós" (ibidem, p. 19). Novamente, podemos aplicar essa noção a uma sociedade em particular, a sociedade científica, na qual cada cientista carrega em si as tradições que caracterizam a sua comunidade.

Por fim, temos o operador dialógico, que significa que para compreender alguns fenômenos complexos é necessário juntar duas noções que são, a princípio, antagônicas e, ao mesmo tempo, complementares. Ressaltamos a potência desse operador para o 
ensino de ciências, visto que os temas metacientíficos ainda estão (e provavelmente permanecerão) sujeitos a ambiguidades e discordâncias entre os teóricos. O modo como os conhecimentos científicos e as ciências como atividade humana são compreendidos atualmente pelos especialistas variam e chocam-se em muitas direções. Pode parecer paradoxal e inconcebível que um paradigma construtivista, por exemplo, possa coexistir com os vários tipos de realismo científico, ambos oferecendo leituras coerentes e bem estruturadas sobre a construção do conhecimento científico. No entanto, "O princípio dialógico não opõe ordem e desordem, natureza e cultura, mas entende tais fenômenos como simultaneamente concorrentes, antagônicos e complementares, o que permite manter a dualidade no seio da unidade" (ALMEIDA et al., 1997, p. 33). Não obstante, Morin coloca-se explicitamente a favor de uma educação transdisciplinar, que se opõe à disjunção dos saberes promovida pela forte disciplinarização do conhecimento. Na tradição disciplinar da escola - bem como do pensamento científico em geral - tendemos a esquecer que os acontecimentos estão mesclados, imbricados com grande diversidade de análises possíveis. A separação em áreas do saber é artificial, feita geralmente para facilitar a abordagem do problema a partir de recortes específicos. Morin não recusa a importância das ferramentas cognitivas que "recortam" os problemas, apenas relembra a importância de se possuir também as ferramentas que permitam religar essas dimensões para a análise complexa (MORIN, 2000; 2003). Nesse contexto, cabe destacar que a transdisciplinaridade se vale da transferência de conceitos e, muitas vezes, da construção de analogias e metáforas, amplificando e multiplicando as possibilidades de significação de termos científicos.

Esperamos que nossa intenção tenha ficado clara: almejamos que o ensino de Termodinâmica possa ser um meio para a construção do pensamento complexo, uma nova ética do saber, útil à educação científica e à resolução de problemas da vida pessoal e social. Certamente, Edgar Morin tem seu pensamento influenciado pelo pensamento científico, dados alguns dos termos mobilizados por sua filosofia. Pensamos, por isso, que há espaço no ensino da Termodinâmica, tanto na educação básica como superior, para discussão de conceitos fundamentais tanto à compreensão da teoria, como à articulação com os operadores complexos e suas possíveis aplicações. Haveríamos de dispor de muitos mais parágrafos para entretecer os fios do pensamento moriniano com aqueles das demandas da educação científica. No entanto, esperamos ter indicado alguns entrelaçamentos contidos na filosofia da complexidade e na proposta de ensino e aprendizagem das ciências. 


\section{Conclusão}

O mais recente relatório do Painel Intergovernamental sobre Mudanças Climáticas (IPCC), de agosto de 2021, afirma que é inequívoca a participação humana nas alterações climáticas dos últimos 2000 anos e que quase a totalidade das emissões de gases do efeito estufa é de responsabilidade dos humanos. Os diagnósticos indicam que já nos encontramos em um "ponto de não retorno", uma situação irreversivel (IPCC, 2021). Por isso, a mudança climática é uma das emergências planetárias que merecem atenção e reconhecimento da população para que haja participação de todos os setores nesse debate de interesse global. Diante dessa crise ambiental e humanitária, buscamos inspiração no paradigma da incerteza e no pensamento complexo para compreender nossa posição como indivíduos na sociedade planetária. Usando a potência da metáfora, afirmamos: nós somos como partículas errantes no mundo. Mas aprendemos com a visão fenomenológica da Termodinâmica que um grande conjunto de partículas, mesmo que microscopicamente desordenadas e caóticas, apresentam características emergentes ordenadas. Por ora, podemos apenas imaginar o tipo de ordenamento espontâneo que poderia emergir de uma sociedade altamente entrópica como a nossa, cujas conexões são fortemente intrincadas, persistentes e de intenso fluxo de informação. A partir do que Ilya Prigogine informa sobre os sistemas abertos longe do equilíbrio, em que a matéria começa a ver a si mesma, transformando-se em complexos arranjos espaciais (PRIGOGINE; FERREIRA, 1996, p. 71), nos inspiramos na possibilidade de que uma sociedade mais consciente de si construa um vir-a-ser muito diferente do atual, jamais imaginado.

Localizamo-nos historicamente no campo de Ensino de Ciências quanto ao caminho já percorrido para que as soluções propostas para tais questões e urgências contemporâneas não incorram em problemas antigos, até superados. Assim, defendemos o ensino do conhecimento científico via História e Filosofia das Ciências, a partir de temas mobilizados pela Natureza das Ciências, bem como outras abordagens contextuais que destacam a natureza de conhecimento científico. Elucidar, a partir da abordagem explícita de elementos metacientíficos do saber, que o sistema de dependência epistêmica da comunidade acadêmica e seu compromisso para com a sociedade no geral é o que garante qualidade e um saber confiável, oferecendo uma cultura científica útil a todos e todas. É exatamente porque existem 
as incertezas, flutuações e mudanças na história do pensamento, que os diferentes métodos adotados pelos cientistas podem, por vezes, convergir em uma compreensão compartilhada e confiável do mundo. Almejamos, em futuros trabalhos, aproximar mais profundamente conceitos tanto da físico-química desenvolvida por Ilya Prigogine quanto dos escritos de Edgar Morin. Finalizamos com Morin, que sintetiza maravilhosamente nosso pensamento: "o único conhecimento válido é aquele que se nutre de incerteza e que o único pensamento que vive é aquele que se mantém na temperatura de sua própria destruição" (MORIN et al., 2003, p. 31).

\section{Teaching History and Philosophy of Thermodynamics as means for complex thinking}

\section{Abstract}

This paper presents elements for teaching school grade Thermodynamics and its related Teacher Training programs, prioritizing transdisciplinarity and other debates regarding attitudes towards contemporary pressing issues such as climate change. We take as starting points some discussions around Scientific Literacy (SL) and Nature of Science (NOS) - a field that emerges in the intersection between History and Philosophy of Science (HPS) and Science Teaching (ST). The present research makes a case towards the rupture of old and frail paradigms which still permeate and silently conduce our worldview. We argue that the insistence on such paradigms frequently denies the benefits of a more critical, integrative, and scientific attitude, informed on the world's meanders and complexities of human action. Our preference for the NOS approach is justified by its focus on pedagogical actions aligned with science's contemporary philosophical and historiographical conceptions. Our research is based on Ludwik Fleck's epistemological contributions, drawing possible relations between Thermodynamic theories and Edgar Morin's complex thinking. Such approximations may be resourceful to the objectives of SL: preparing citizens for informed and socially referenced decision-making around planetary crises that call for proactive stances.

Keywords: Science Teaching, Nature of Science, History of Thermodynamics, uncertainty, complexity.

\section{Nota}

1 "É a única teoria física relativa a um conteúdo universal a qual eu estou convencido que, dentro dos limites de aplicação dos seus conceitos básicos, nunca será derrubada”.

2 A teoria do calórico é uma teoria material sobre a natureza do calor. Originou-se no século XVIII nas interfaces entre o que viriam a ser consideradas a Física e a Química Modernas e tratava o calórico como um fluido imponderável presente em toda a matéria, que supunha-se estar relacionado e entremeado à estrutura molecular. Na teoria do calórico, o calor era tratado ao mesmo tempo como uma função de estado e uma quantidade conservada nos processos de transformação de energia (PÁDUA et. al., 2008). 
À semelhança da lei de conservação de energia, que estava sendo elaborada ao mesmo tempo que a do calórico, o calor total do universo seria conservado. Uma das dificuldades para a aceitação da teoria do calórico, foi a impossibilidade de explicar a produção de uma quantidade inesgotável do calórico a partir do atrito (entre as mãos, por exemplo), fenômeno que violaria a lei de conservação.

\section{Referências}

ALMEIDA, Maria da Conceição X; CARVALHO, Edgar A; CASTRO, Gustavo. Ensaios de Complexidade, Porto Alegre: Sulina, 1997.

ADÚRIZ-BRAVO, Agustín. Teaching the nature of science with scientific narratives. Interchange, v. 45 , n. $3-4$, p. $167-184,2014$.

AURANI, Katya M. As ideias iniciais de Clausius sobre entropia e suas possíveis contribuições à formação de professores. Revista Brasileira de História da Ciência, v. 11, n. 1, p. 155-63, 2018.

CLOUGH, Michael. P. History and nature of science in science education. In: Science Education. Sense Publishers, Rotterdam, 2017. p. 39-51.

CONDÉ, Mauro Lúcio L. Mutações no estilo de pensamento: Ludwik Fleck e o modelo biológico na historiografia da ciência. Revista de Filosofia Moderna e Contemporânea, v. 6, n. 1, p. 155-186, 2018.

DELIZOICOV, Demétrio et al. Sociogênese do conhecimento e pesquisa em ensino: contribuições a partir do referencial fleckiano. Caderno Brasileiro de Ensino de Física, v. 19, p. 52-69, 2002.

EL-HANI, Charbel N. Notas sobre o ensino de história e filosofia da ciência na educação científica de nível superior. Estudos de história e filosofia das ciências: subsídios para aplicação no ensino. São Paulo: Editora Livraria da Física, p. 3-21, 2006.

HARAWAY, Donna. Saberes localizados: a questão da ciência para o feminismo e o privilégio da perspectiva parcial. Cadernos Pagu, n. 5, p. 7-41, 2009.

HODSON, Derek. Philosophy of science, science, and science education. Studies in Science Education, University of Leeds, v. 12, p. 25-57, 1985.

HÖTTECKE, Dietmar; ALLCHIN, Douglas. Reconceptualizing nature of science education in the age of social media. Science Education, v. 104, n. 4, p. 641-666, 2020.

IPCC, Summary for Policymakers. Climate Change 2021: The Physical Science Basis, Cambridge University Press, 2021.

JAPIASSÚ, Hilton; MARCONDES, Daniel. Dicionário Básico de Filosofia. Rio de Janeiro: Jorge Zahar Editor Ltda, 2008.

KLEIN, Martin J. Thermodynamics in Einstein's thought. Science, v. 157, n. 3788, p. 509-516, 1967.

LEDERMAN, Norman G. et al. Views of nature of science questionnaire: Toward valid and meaningful assessment of learners' conceptions of nature of science. Journal of research in science teaching, v. 39, n. 6, p. 497-521, 2002.

MATTHEWS, Michael S. História, filosofia e ensino de ciências: a tendência atual de reaproximação. Caderno Brasileiro de Ensino de Física, v. 12, n. 3, p. 164-214, 1995. 
MARÍN, Nicolás et al. Revisión de consensos sobre naturaleza de la ciencia. 2013.

MARTINS, André F. P. Natureza da Ciência no ensino de ciências: uma proposta baseada em "temas" e "questões". Caderno Brasileiro de Ensino de Física, v. 32, n. 3, p. 703-737, 2015.

MOREIRA, Marco Antônio. Ensino de Física no Brasil: retrospectiva e perspectivas. Revista Brasileira de Ensino de Física, v. 22, n. 1 (mar. 2000), p. 94-99, 2000.

MORIN, Edgar. A cabeça bem-feita. Bertrand Brasil, Rio de Janeiro, v. 99, 2000.

MORIN, Edgar; CIURANA, Emilio R.; MOTTA, Raúl D. Educar na era planetária: o Pensamento complexo como método de aprendizagem pelo erro e incerteza humana. Cortez, Setembro, 2003.

MOURA, Breno Arsioli. O que é natureza da Ciência e qual sua relação com a História e Filosofia da Ciência. Revista Brasileira de História da Ciência, v. 7, n. 1, p. 32-46, 2014.

PÁDUA, Antonio B. et al. Termodinâmica clássica ou termodinâmica do equilíbrio: aspectos conceituais básicos. Semina: Ciências Exatas e Tecnológicas, v. 29, n. 1, p. 57-84, 2008.

PEDUZZI, Luiz O. Q.; RAICIK, Anabel C. Sobre a natureza da ciência: asserções comentadas para uma articulação com a história da ciência. Investigações em Ensino de Ciências, v. 25, n. 2, p. 19-55, 2020.

PÉREZ, Daniel Gil et al. Para uma imagem não deformada do trabalho científico. Ciência \& Educação (Bauru), v. 7, p. 125-153, 2001.

PRAIA, João; GIL-PÉREZ, Daniel; VILCHES, Amparo. O papel da natureza da ciência na educação para a cidadania. Ciência \& Educação, v. 13, p. 141-156, 2007.

PRIGOGINE, Ilya; STENGERS, Isabelle. Order out of chaos: Man's new dialogue with nature. Bantam Books, 1984.

PRIGOGINE, Ilya; FERREIRA, R. L. O fim das certezas. Unesp, 1996.

ROSA, Luiz P. Tecnociências e humanidades: novos paradigmas, velhas questões, o determinismo newtoniano na visão de mundo moderna. Editora Paz e Terra, 2006.

SASSERON, Lúcia H; CARVALHO, Anna Maria P. Alfabetização científica: uma revisão bibliográfica. Investigações em Ensino de Ciências, v. 16, n. 1, p. 59-77, 2011.

SCHULZ, Peter A. Duas nuvens ainda fazem sombra na reputação de Lorde Kelvin. Revista Brasileira de Ensino de Física, v. 29, p. 509-512, 2007.

TEIXEIRA, Elder S.; FREIRE JR, Olival; EL-HANI, Charbel Niño. A influência de uma abordagem contextual sobre as concepções acerca da natureza da ciência de estudantes de física. Ciência \& Educação, v. 15, n. 3, p. 529-556, 2009.

VIDEIRA, Antonio Augusto P. Boltzmann, física teórica e representação. Revista Brasileira de Ensino de Física, v. 28, p. 269-280, 2006. 